\title{
Reflexões sobre a relação entre a (des)construção do espaço público e a (sub)cidadania
}

Reflections on the relationship between the (non) formation of public areas and the (sub-)citizenship

\author{
Priscila Maria de Freitas
}

\section{Maria Aparecida Chaves Ribeiro Papali}

\section{Mário Valério Filho}

Universidade do Vale do Paraíba - UNIVAP

\begin{abstract}
Resumo: As cidades brasileiras contemporâneas possuem espaços que ora privilegiam a realização de negócios e ora a construção de cidadania. Para compreender como são ocupados destes modos se faz necessário analisar as cidades; desde sua definição, passando pelo contexto político e econômico, para então compreender seu aspecto social. Assim, este artigo busca compreender se e em que medida as características dos espaços públicos impactam no processo de construção de cidadania. Analisando por meio de observação flutuante dois espaços públicos que são duas praças urbanas centrais, localizadas em duas cidades no mesmo contexto metropolitanos. Perpassa-se pelo debate regional com o intuito de evidenciar que os conflitos são equivalentes nas diversas escalas; contudo a demonstração do contexto da Região Metropolitana do Vale do Paraíba e Litoral Norte/SP, objetiva tornar evidente que as estruturas físicas locais, dos espaços públicos urbanos centrais não direcionam as relações sociais e suas disputas, mas são um meio e resultado dessas.
\end{abstract}

Palavras-chave: Cidade. Espaço público. Cidadania.

\begin{abstract}
The contemporary Brazilian cities have areas that sometimes favor the business fulfillment and sometimes the citizenship formation. In order to understand how these are occupied its necessary the cities analysis; from definition, through the political and economic context, to then understand the social aspect. Thus, this article seeks to understand how the characteristics of public areas impact on the process of citizenship formation. By floating observation analysis carried out in two public areas that are two urban central squares, located in two cities in the same metropolitan context. The regional debate is unfolded in order to evidence that conflicts are equivalent on different scales; however, the demonstration of Metropolitan Region of Vale do Paraíba e Litoral Norte/SP context aims to make evident that the local physical structures of urban central public areas do not direct social relations and their disputes, but are an environment and result of them.
\end{abstract}

Keywords: City. Public areas. Citizenship. 


\section{Introdução}

As cidades brasileiras contemporâneas possuem espaços que ora privilegiam a realização de negócios e a reprodução do capital, ora a construção de cidadania. Nessa disputa entre a city e a polis, estão os sujeitos que em vários momentos tomam atitudes de consumidores e/ou usuários, e em outros tais sujeitos se posicionam como cidadãos. Nesse sentido, também deve-se considerar a postura de um agente social relevante no contexto da vida em sociedade, o Estado. Em virtude do Estado ter sucumbido à lógica mercadológica corre-se o risco de considerar todos os espaços da cidade como propícios apenas aos interesses capitalistas. Sendo isso verdade, onde estão os lugares de construção de cidadania? Como é possível identificar tais lugares no nosso contexto urbano contemporâneo? Quanto às práticas de cidadania, dadas nos espaços públicos, seriam elas influenciadas pelas características físicas do espaço público e seu contexto socioeconômico?

Responder essas questões exige, primeiramente, compreender esses espaços sociais, ou seja, entender como são construídos e ocupados os espaços públicos das cidades brasileiras contemporâneas. Essa possibilidade cidadã é construída tanto pelo espaço público, quanto pelo contexto das relações sociais dadas nesse espaço? Se o for, a politização do espaço e dos sujeitos se faz relevante.

Para tanto, apresenta-se o conceito de cidade que é composto pela função do Estado, tendo a cidade como centro administrativo e de poder; o território da cidade e suas representações, passando pela compreensão de sociedade e de cidadania, com os espaços gerados e geridos por esse coletivo, com seus símbolos e representações de cada lugar (espaço público) nessa cidade.Atualmente o Estado brasileiro está em consonância com o sistema capitalista, mais especificamente no momento neoliberal do sistema, gerando uma lógica de competição entre entes federados. Assim, as cidades competem entre si dentro da lógica mercadológica, gerando uma ausência de práticas solidárias e a despolitização do espaço social. Essas ações institucionais são também as ações dos sujeitos, ou seja, os sujeitos tendem pela "substituição do engajamento e mútuo comprometimento pelas técnicas do desvio e da evasão" (BAUMAN 2001, 127).Apesar desse panorama de polis encontrar-se diluída na dinâmica hegemônica da city, é relevante lembrar que as cidades não foram instituídas com a finalidade econômica ou política, mas sim voltadas para possibilitar locais de encontro e de troca entre os semelhantes. As cidades são espaços onde os lugares são construídos, onde os pedestres, segundo Michel de Certeau (1994) demarcam cotidianamente seus territórios, em um processo real e simbólico de busca por significados emancipatórios em relação ao avanço hegemônico do capital.

Com o objetivo de compreender as relações existentes entre as características dos espaços públicos e o processo de construção (ou constituição) de cidadania, esse estudo utilizou-se da observação flutuante. O propósito da etnografia urbana "não é discutir a ordem internacional e sim delimitar um campo onde se possam apreciar alternativas de análise voltadas para a dinâmica urbana contemporânea" (MAGNANI, 2002, p. 14). Qual seja, analisar a dinâmica urbana de duas cidades que se encontram no mesmo contexto metropolitano, mas são consideradas cidades antagônicas. Para encontrar dentro de uma mesma região metropolitana duas cidades díspares, foram analisadas inicialmente as dimensões territoriais e densidades demográficas dos municípios que compõem a Região Metropolitana do Vale do Paraíba e Litoral Norte, chegando às cidades de São José dos Campos e de Natividade da Serra, que possuem dimensões territoriais equivalentes e 
densidades populacionais opostas. No decorrer deste artigo também se demonstram os conflitos na escala regional, com as respectivas relações dadas entre as duas cidades analisadas, contudo 0 enfoque deste trabalho está na escala local e os desdobramentos no espaço público urbano e suas formas de apropriações.

\section{Cidade: locus de construção de cidadania?}

Conforme o Censo de 2010, o IBGE afirma que $84,35 \%$ da população brasileira reside em áreas urbanas. Agora, em 2019, em virtude das dinâmicas vivenciadas nesta última década, provavelmente esta porcentagem seja maior; tal fato traz a reflexão como estão se formando estas áreas urbanas? Será que estes espaços possuem características de city ou da polis? Segundo Vainer estas características seriam antagônicas, ao conceituar que "de um lado, a city, impondo-se à cidade como espaço e objeto e sujeito de negócios; de outro lado, a polis, afirmando a possibilidade de uma cidade como espaço do encontro e confronto entre cidadãos" (2002, p.101).

Para desenvolver essas questões tem-se primeiramente que compreender a conceituação de cidade. Inicialmente a cidade pode ser conceituada como "centro e expressão de domínio sobre o território, sede do poder e da administração, lugar da produção de mitos e símbolos" (ROLNIK, 1995, p. 8), ou seja, entende-se a cidade como centro administrativo, sede de poder e lugar de concentração das tomadas de decisões; desta forma, também se torna um símbolo de domínio, ora político administrativo, ora econômico.

Este conceito condiz com a atual dinâmica capitalista globalizada das cidades contemporâneas, cujos espaços se (re)produzem pelo viés econômico, com aporte político; mesmo trazendo consigo todas suas mazelas sociais. Nesse sentido, Hillman reflete que nem sempre as cidades foram conceituadas assim, uma vez que "pensar o propósito das cidades ser econômico ou político é uma ideia, sem dúvida, muito recente. Desde o início, o propósito da construção de uma cidade foi algo instintivo nos seres humanos: querer estar junto, imaginar, falar, fazer e trocar" (HILLMAN 1993, 41). Á vista disto, a cidade também pode ser entendida como o lugar nos quais se dão encontros e confrontos entre cidadãos, uma compreensão dada por Bauman.

Na clássica definição de Richard Sennett,
uma cidade é um assentamento humano
que estranhos têm a chance de se
encontrar. (...). O encontro de estranhos é
um evento sem passado. Frequentemente é
também um evento sem futuro (o esperado
é não tenha futuro), uma história para "não
ser continuada", uma oportunidade única a
ser consumada enquanto dure e no ato, sem
adiamento e sem deixar questões
inacabadas para outra ocasião. (BAUMAN,
2001, p. 111)

Portanto, a cidade seria entendida como lócus de expressão de domínio do território e gerador de símbolos, possibilitando o surgimento de espaços públicos com estruturas tais que permitam ou inibam o encontro entre diferentes sujeitos. Neste contexto, compreende-se o sujeito como aquele que se preocupa apenas com as suas inquietudes, suas angústias e com as formas de saná-las individualmente; enquanto o cidadão, possuindo a arte do diálogo e da negociação, se atenta para as questões coletivas, nas quais estão inseridos ele e diversos estranhos. Assim essa característica de civilidade seria definida como "a capacidade de interagir com estranhos sem utilizar essa estranheza contra eles e sem pressioná-los a abandoná-la ou a renunciar a alguns dos traços que os fazem estranhos" (BAUMAN 2001, 122).

Esse local de encontro entre estranhos, onde o espaço físico possibilita a troca de olhares, de conversa e de ideias; seriam estes espaços físicos que compõem os espaços públicos das áreas urbanas contemporâneas? Se assim o forem, estes espaços públicos seriam uma releitura contemporânea da ágora grega? Ou seja, se 
tratariam de espaços públicos que possibilitassem esses encontros entre estranhos, propiciando aos cidadãos compartilharem suas questões coletivamente, a polis afirmada por Vainer?

Bauman subsidia a compreensão das áreas urbanas existentes na pós modernidade (ou modernidade líquida) e suas singularidades, contudo, como o debate proposto neste artigo se refere a apropriação do espaço público nestas áreas urbanas e a uma percepção de cidadania dada por esta apropriação, é necessário o aporte de outros autores como Lefebvre, Mongin, Jessé Souza e Boaventura de Sousa Santos.

Com as considerações traçadas até aqui, uma resposta se faz possível, cidade é sinônimo de complexidade. Qual seja, o tecido da urbe não se constrói só de pedras e cimento, a ele se conjugam homens e mulheres, cidadãos, marginalizados, toda uma gama de sujeitos que ora se submetem aos ditames do capital, ora o subvertem na busca pela construção da cidadania. Segundo Lefebvre "A vida urbana pressupõe encontros, confrontos das diferenças, conhecimento e reconhecimento recíprocos (inclusive no confronto ideológico e político) dos modos de viver, dos "padrões" que coexistem na Cidade" (LEFEBVRE, 2001, p. 22).

Um fator que compõem a construção da cidade é a luta pelos e nos lugares (LEFEBVRE, 2006), é a cidade como lócus e objeto das disputas cotidianas. E no contexto deste cotidiano, com os modos de viver ou este "padrões" que demandam locais de convivência, se encontra o debate da city e da polis, ou seja, espaços dos sujeitos de negócios ou espaços do debate entre cidadãos.

Mongin demonstra que o estabelecimento da cidadania passa pela construção de locais que possibilitem o encontro e confronto entre os semelhantes; os quais, mesmo com as suas diferenças, reconheçam-se. "É esta a condição política prévia do urbano contemporâneo: se o espaço comum não é mais a regra, entidades políticas e espaços unificadores devem ser criados ou recriados. Como dizem alguns, 'a luta de classes foi substituída pela luta dos lugares"” (MONGIN, 2009 , p. 23). A partir desta colocação de Mongin duas compreensões podem se dar. A primeira se relaciona aos espaços públicos entendidos sobre o olhar da teoria do comum de Dardot e Laval (2017), que entendem o comum como uma conjuntura de lutas dadas por práticas cotidianas e conscientes de um coletivo que abrem as portas para um futuro não capitalista, ao se responsabilizarem pelas decisões tomadas no e pelo coletivo. Desta forma, o espaço público seria o local onde estes coletivos abrigariam os debates políticos.

Por este olhar o espaço público, no caso a praça nos centros urbanos, se faz palco para os debates sobre a teoria do comum. Mas apenas a existência de tais lugares (como as praças) pode ser considerado como um fator no processo de construção de cidadania? Tal reflexão leva a próxima e complementar compreensão possível da citação do Mongin. Os espaços unificadores assim o são por serem um reflexo de uma modificação política do indivíduo. Como atesta Milton Santos, "o homem livre nasce com a desalienação e se afirma no grupo. O cidadão, porém, é uma categoria política que só tem eficácia enquanto categoria jurídica" (SANTOS 2000, 79). A luta pela cidadania é constante, que pode se pautar por um momento jurídico, por uma lei ou instrumental existente, contudo "assim como o indivíduo deve estar sempre vigiando a si mesmo para não se enredar pela alienação circundante, assim o cidadão, a partir das conquistas obtidas, tem que permanecer alerta para garantir e ampliar sua cidadania" (SANTOS 2000, 80).

E tal cidadania só pode ser imaginada de forma concreta se somada ao componente territorial (SANTOS, 2000, p. 116). E isto implica ir além da dicotomia indivíduo e sociedade, demandando na compreensão desta sociedade, em todo o seu contexto, como na sua formação histórica, seus simbolismos e sua construção social. Jessé Souza 
(2006) auxilia numa compreensão crítica a partir reinterpretação da formação social do Brasil, afirmando que a desigualdade social no país é naturalizada por meio de um arsenal de justificativas que obscurecem a real condição de precariedade de uma parcela da população. Assim, cotidianamente permanecesse invisível a existência de pessoas pobre e miseráveis, sob o discurso, por exemplo, de meritocracia. Neste contexto, Souza afirma a construção social de subcidadania, ou seja, "habitus precário" ou uma personalidade improdutiva, que não se adaptou ao modelo hegemônico e, portanto, marginalizada do reconhecimento subjetivo e coletivo de uma identidade aclamada, resultando na condição de subcidadão; formando o que o autor denomina de "ralé estrutural" nas sociedades periféricas.

Souza estrutura a sua tese ao analisar o Brasil e sua formação histórica e se apoiando no conceito de habitus de Pierre Bourdieu em conjunto com reflexões de Charles Taylor acerca da singularidade que as questões culturais $e$ simbólicas. Assim Souza propõem a existência de um "habitus primário" considerado como o homem útil e reconhecido como tal pela racionalidade econômica dominante gera um padrão de conduta na sociedade, fato que garante a este homem direitos e a condição de cidadão. Os que não se enquadram em tal padrão não falado, mas reconhecido coletivamente, são marginalizados e considerados como "habitus precário". Na outra extremidade, ou seja, acima do "habitus primário" estariam aqueles que disputam pelo ditame da cultura, pelo reconhecimento dos estilos de vida a serem seguidos na sociedade, se assemelhando ao que Bourdieu denomina de "gosto". Desta forma, Jessé Souza, demonstra como se dá a aceitação coletiva de diferentes valores para os seres humanos legitimando, de forma velada, a desigualdade social.

Esta compreensão proposta por Jessé Souza vem a somar no debate das epistemologias do sul de Boaventura de Sousa Santos (2007), ao propor a existência (ou a persistência em existir) da linha abissal que demarcavam o Velho e o Novo Mundo na era colonial. Assim o sendo, permanece a divisão do mundo e, consequentemente, em todos os espaços e relações o "lado de cá" e o "outro lado".

\begin{abstract}
A divisão é tal que "o outro lado da linha" desaparece como realidade, torna-se inexistente e é mesmo produzido como inexistente. Inexistência significa não existir sob qualquer modo de ser relevante ou compreensível. Tudo aquilo que é produzido como inexistente é excluído de forma radical porque permanece exterior ao universo que a própria concepção de inclusão considera como o "outro". A característica fundamental do pensamento abissal é a impossibilidade da co-presença dos dois lados da linha.O universo "deste lado da linha" só prevalece na medida em que esgota o campo da realidade relevante: para além da linha há apenas inexistência, invisibilidade e ausência não-dialética. (SANTOS, 2007, p. 71)
\end{abstract}

Por este conceito, também reconhece-se a existência e legitimação da desigualdade social, contudo se propõem uma modificação na sociedade a partir da estruturação dos saberes, ou por meio da epistemologia que aprende que existe o Sul, que aprende a ir para o Sul, e, por fim, aprende a partir do Sul e com o Sul (Santos, 1995, 508). Pressupõem-se que não há neutralidade na construção do conhecimento humano, pelo contrário, tais conjuntos cognitivos ocidentais modernos expressam e validam a discriminação, a marginalização, a desigualdade social.

\section{Cidade, espaço público e cidadania: conflitos em diferentes escalas?}

Dentro do contexto teórico tratado foi proposto dois momentos de experiências, e não experimentos, conforme conceitua Boaventura. $\mathrm{Ou}$ seja, realizar uma vivência num determinado local, objetivando ao levantamento de conhecimento específico para a elaboração de um trabalho 
acadêmico, mas reconhecendo as limitações do pesquisador frente e no objeto pesquisado. Para tanto, utilizou-se a metodologia da observação participante, mais especificamente da observação flutuante.

[a observação flutuante] consiste em permanecer vago e disponível em toda a circunstância, em não mobilizar a atenção sobre um objeto preciso, mas em deixá-la "flutuar" de modo que as informações o penetrem sem filtro, sem a priori, até o momento em que pontos de referência, de convergências, apareçam e nós chegamos, então, a descobrir as regras subjacentes. (PÉTONNET, 2008, p. 102)

Esta metodologia consiste em observar a paisagem e sua dinâmica, também chamada de olhar a paisagem por José Magnani, pois consiste em "percorrer a cidade e seus meandros observando espaços, equipamentos e personagens típicos com seus hábitos, conflitos e expedientes, deixando-se imbuir pela fragmentação que a sucessão de imagens e situações produz" (MAGNANI, 2002, p. 18). Gerando um relato que expresse tais experiências, sem a intensão de defini-las intimamente, mas se configura numa leitura da dinâmica urbana contemporânea.

Com esta metodologia foram analisadas as duas praças de cidades diferentes. Desta forma, realizou-se um estudo comparativo entre duas cidades que possuíssem algumas semelhanças (como a ligação histórica do surgimento do contexto urbano com a praça central, ou a dimensão territorial), mas com realidades díspares (como a dinâmica econômica e a representação social no contexto metropolitano), inseridas no mesmo contexto metropolitano, já que ambas estão localizadas na Região Metropolitana do Vale do Paraíba e Litoral Norte, conhecida oficialmente como RMVPLN, mas será aqui citada também como RMVale. A escolha dessas duas cidades se deu a partir de uma análise inicial das dimensões territoriais e densidades demográficas dos municípios, já que as densidades populacionais demonstram o grau de adensamento e concentração ou não de infraestrutura urbana e de serviços.

Ao se buscar os cinco maiores municípios da RMVale em extensão territorial encontra-se as cidades de Cunha, São José dos Campos, Natividade da Serra, Paraibuna e Guaratinguetá Observando as densidades demográficas e buscando dentre esses cinco municípios o de maior e menor densidade tem-se respectivamente São José dos Campos com 633,06 hab/Km² e Natividade da Serra com 8,12 hab/Km². É interessante notar que a dimensão territorial de São José dos Campos é de $1.099,40 \mathrm{Km}^{2}$ e Natividade da Serra possui $833,37 \mathrm{Km}^{2}$, ou seja, apesar de possuírem dimensões territoriais relativamente próximas, são díspares no que se refere a concentração populacional. Outro fato interessante é que essas duas cidades apresentam certa proximidade conforme ilustrado na Figura 1, mas possuem uma dinâmica de deslocamento e de infraestrutura bem diferentes, já que São José dos Campos é cortado pela Rodovia Presidente Dutra, fato que representa a conexão com os centros de decisões econômicas do país (ligação com as cidades e regiões metropolitanas de São Paulo e Rio de Janeiro); enquanto Natividade da Serra não possui conexões de mobilidade tão expressivas economicamente, e sim, abriga no seu território o represamento das águas do Rio Paraibuna, importante social e economicamente para a região. 
Figura 1 - Localização dos municípios na RMVale.

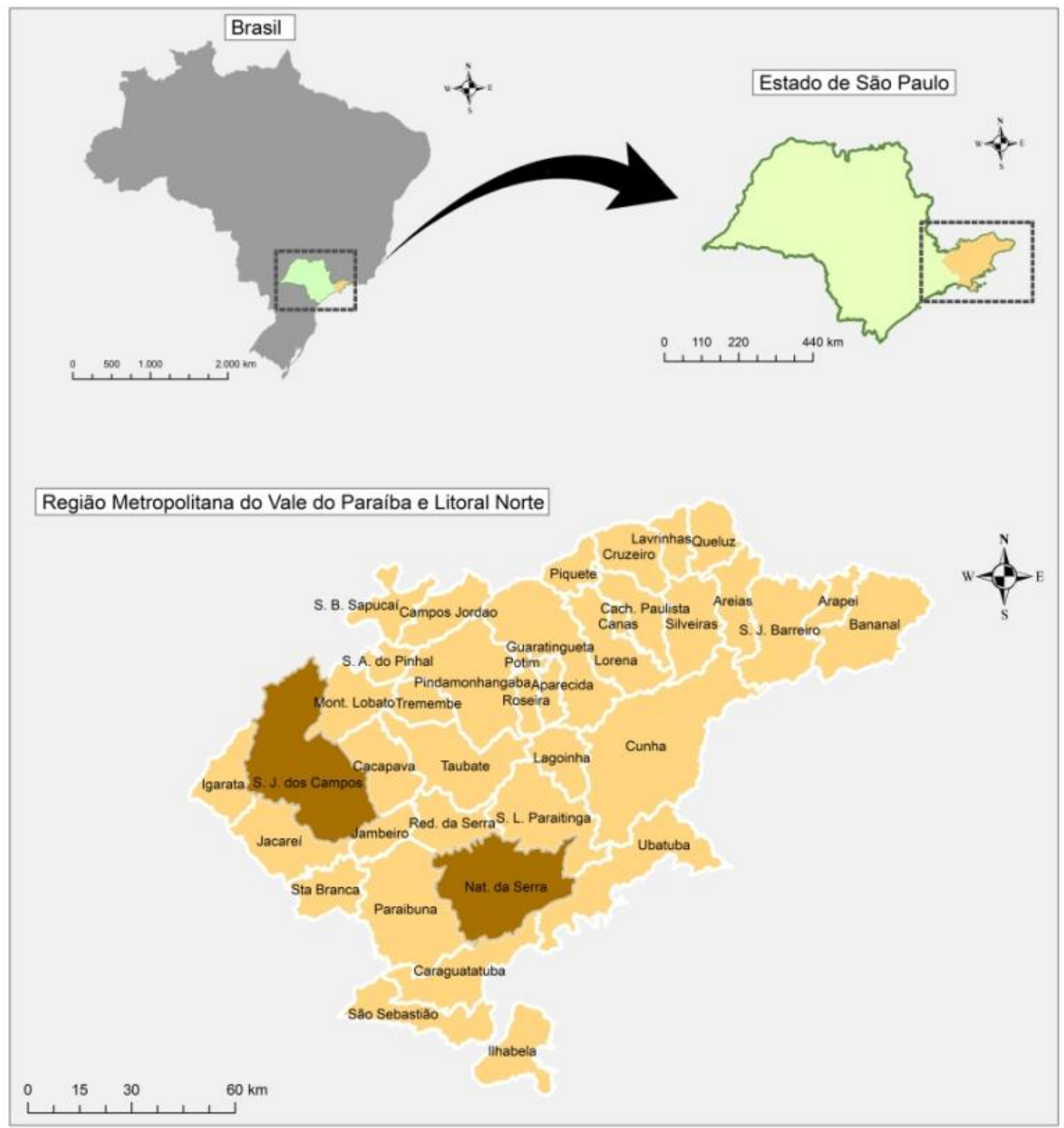

Fonte: Adaptado de Kurkdjian et al. 1992 e de IBGE 2010

Assim foram elencadas as praças públicas centrais das cidades de São José dos Campos (sede desta região metropolitana) e de Natividade da Serra (cidade considerada não relevante no contexto econômico ou turístico desta região), visando compreender se e em que medida as características dos espaços públicos impactam no processo de construção de cidadania.
A Praça Afonso Pena é delimitada por quatro ruas paralelas, formando um retângulo e de piso plano. Fica localizada no centro histórico da cidade de São José dos Campos, sendo uma referência de localização e eventos para os moradores da cidade. Pela visualização da Figura 2 constata-se 0 adensamento verticalizado no entorno da praça representado pelos vários edifícios e pela proximidade entre eles. 
Figura 2 - Vista aérea com a delimitação do perímetro da Praça Afonso Pena, localizada na região central da cidade de São José dos Campos/SP

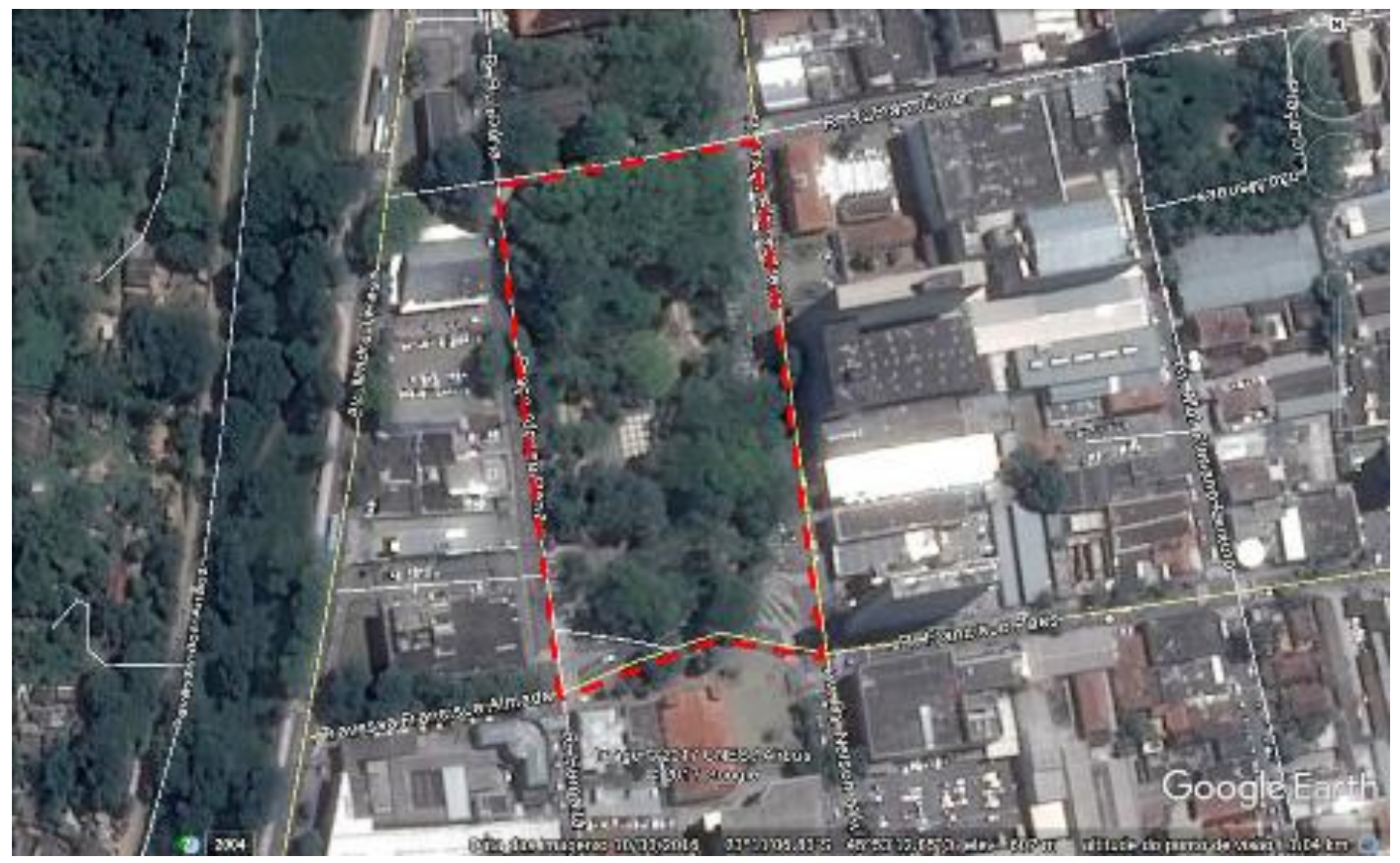

Fonte : Adaptado de Google Earth (acesso 12 de junho de 2017)

A pesquisa por meio da observação flutuante realizada nesta praça, num primeiro momento foi percebido que a estrutura física da praça está em bom estado de manutenção, com árvores podadas, bancos espalhados em locais de sombra das copas das árvores e equipamentos, tanto de ginástica quanto infantil, em bom estado de uso. A praça possui uma área aberta própria para eventos e exposições.
Observando a forma de utilização do espaço, foi possível notar que a maioria das pessoas utilizam a praça apenas como local de passagem, já que se situam nesta praça dois pontos de ônibus. Mesmo assim, é possível identificar alguns senhores, que aparentam ter mais de 60 anos, lendo no banco da praça ou se exercitando nos aparelhos de ginástica. Outro fato curioso foi a conversa entre dois jardineiros. Eles permaneceram dialogando durante toda a estadia na praça, ora parados ora trabalhando, mas a interação era ininterrupta.

Figura 3: Praça Afonso Pena: transeuntes e trabalhadores

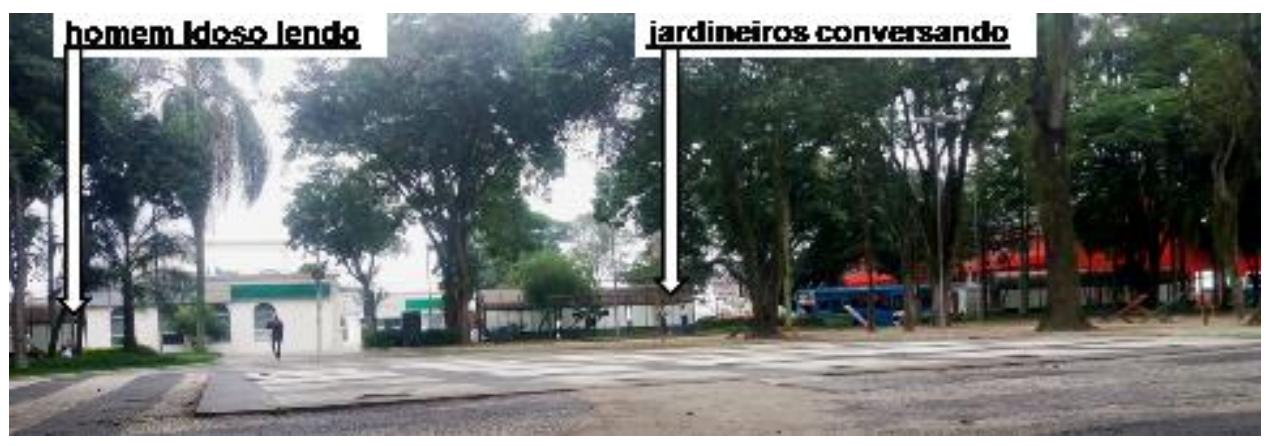

Fonte: Acervo dos autores 
Ao sair de um dos ônibus que paravam bruscamente no ponto, uma mãe com sua filha resolveram brincar por alguns minutos na praça. Naquele momento a praça ganhou um som de risos misturados com os cantos longínquos do "bem-te-ví" e roncos de motores das ruas. A praça se reveste de um sentido de apropriação. Os sujeitos (mãe e filha) se apropriam momentaneamente daquele espaço, construindo, tal qual nos ensina Michel de Certeau (1994) as práticas dos lugares, à medida que seus passos, risos e brincadeiras se entrelaçam, transformando o espaço em lugar.

Poucos minutos antes das 9hs da manhã, começa uma movimentação diferente na praça, como uma mudança para o próximo ato de um teatro. Chegam diversos vendedores ambulantes, um fica próximo do ponto de ônibus vendendo café, leite e pões; tornando-se um suporte para a classe trabalhadora que chegam pelos pontos de ônibus localizados na praça e logo se encaminham aos postos de trabalho na região central da cidade. Há outros ambulantes que começam a se apropriar do espaço público ao sentarem no chão, em diferentes pontos da praça; interessante notar que estes trabalhadores são todos negros ou mulatos. Aparecem também alguns jovens magros também negros, que devido a feição dos rostos, cheiros, postura física, com as roupas todas rasgadas e inquietos (sempre olhando para todos os lados e sem parada no caminhar), geram a imagem de serem dependentes químicos. Neste momento também é notado a presença crescente de mulheres na praça, o que em conjunto com a fama popular da Praça Afonso Pena de São José dos Campos, traz a representação de serem mulheres profissionais do sexo. É como se a praça mostrasse a diversidade de sujeitos que compõe a cidade, estigmatizada em alguns sentidos, mas também central, vívida, palco de toda complexidade urbana, na medida em que os mais antagônicos sujeitos sociais a habitam.

Como observadora do espaço, mas também sendo observada e sem a possibilidade de distanciamento da condição de mulher, a autora se vê inserida no contexto analisado de forma a ser constrangida a se locomover constantemente e não mais permanecer num ponto fixo da praça. Da mesma forma que, de forma consciente ou inconsciente, o homem branco idoso aparentando ser de classe média (pelas vestimentas) que lia calmamente e a mulher asiática idosa que se exercitava se foram deste espaço.

As lojas que circundam a praça agora começam a abrir, e com elas chegam os sons de propaganda dos seus produtos e a chamada ardente pelos clientes. Já não se ouve mais os pássaros. Poucos minutos depois, chega um homem de meia idade num dos cantos da praça e começa a realizar uma pregação evangélica, aparentemente sem um público de ouvintes atentos. Os ruídos dos veículos também aumentam, pois cresce o fluxo de ônibus e carros no entorno. A praça começa a se caracterizar

Figura 4: Ambulantes na Praça Afonso Pena

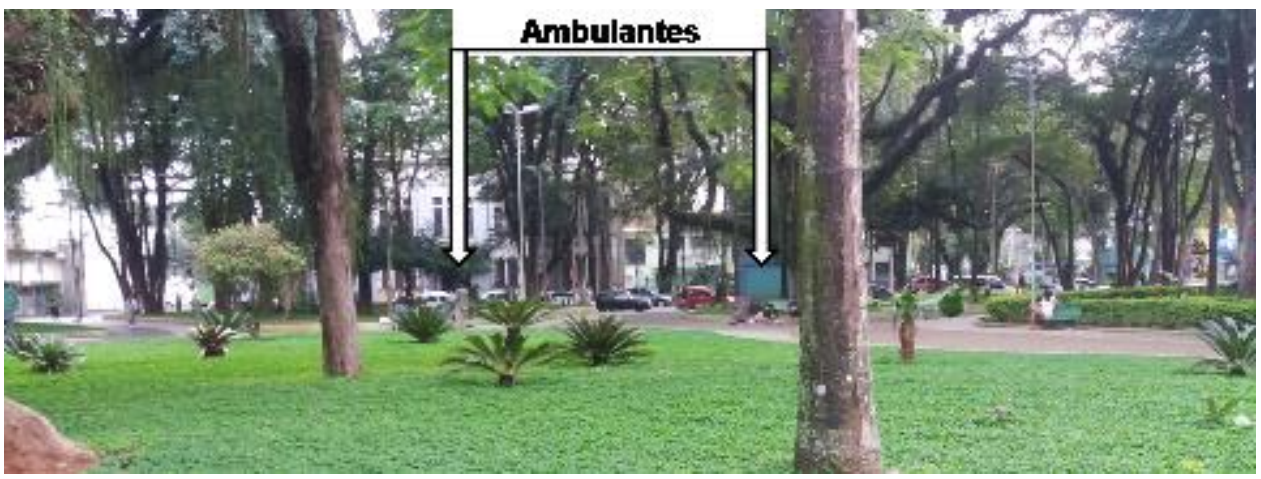

Fonte: Acervo dos autores 
como um local de passagem, com os pontos de ônibus, as lojas e serviços oferecidos ao redor.

A praça observada possui uma dinâmica própria, não influenciada por sua estrutura física e sim pelo contexto urbano no qual está inserida. A realidade constatada na praça se dá em tal espaço devido à localização, sendo uma área central de fácil acesso ao comércio, pontos de ônibus e proximidade com cadeia pública e área de favelização. Ou seja, locais com muitas desigualdades sociais e econômicas, culminando em populações marginalizadas que se apropriam deste espaço público.

Por esse contexto e pelos dados obtidos com a observação, a Praça Afonso Pena localizada no centro da cidade de São José dos Campos, reflete seu aspecto econômico de ser a cidade da região metropolitana que concentra o maior PIB e ter no entorno da sua praça central uma ocupação predominantemente comercial e de serviços. $\mathrm{O}$ aspecto institucional como sede da RMVale, portanto com voz ativa nos debates e direcionamento das políticas públicas, o que gera no seu espaço público central uma disputa pelo discurso predominante, já que foram constatadas diversos usos ocorrendo e uma disputa velada pelo uso tido por "correto", ou seja, o uso socialmente aceito para a praça pública central da cidade.

A Praça Agostinho Felício de Faria é delimitada por cinco ruas e entrecortada por uma, formando um polígono irregular e com o piso em desnível. Fica localizada no novo centro da cidade de Natividade da Serra, que teve o seu centro antigo alagado pelas águas da represa de Paraibuna. Notase a baixa densidade existente no contexto urbano dessa imagem, com edificações térreas e vegetação entre as edificações.

A pesquisa por meio da observação flutuante realizada nesta praça, num primeiro momento foi observado que a estrutura física da praça está em bom estado de manutenção, com um belo paisagismo, com uma variedade de espécies plantadas, que apesar de novas já proporcionavam cores e sombras diferenciadas. A praça é bem extensa e possui muitos bancos, inclusive bancos emparelhados, possibilitando a dinâmica de

Figura 5 - Vista aérea com a delimitação do perímetro da Praça Agostinho Felício de Faria, localizada na região central da cidade de Natividade da Serra/SP.

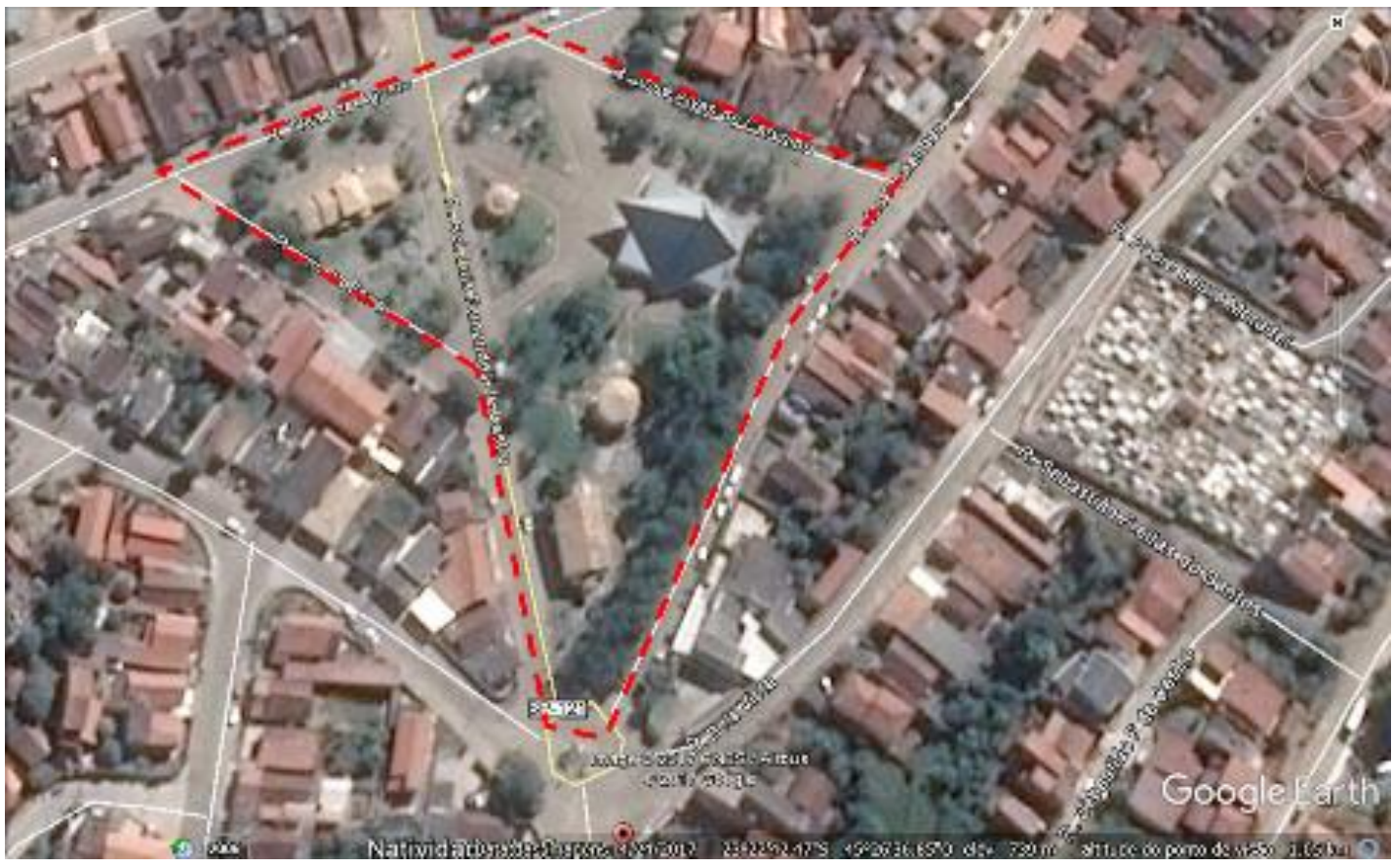

Fonte : Adaptado de Google Earth (acesso 12 de junho de 2017) 
conversa em grupos de aproximadamente oito pessoas.

Pela grande extensão da praça se faz possível essa abrigar muitas construções, como um centro comunitário ativo, uma fonte, um coreto, uma igreja de arquitetura arrojada, uma paróquia, a estátua nomeada de "João Inocêncio", uma rodoviária desativada e equipamentos de ginástica ao ar livre. Essa descrição é a sequência que se encontram as construções ao caminhar a partir da parte baixa da praça.

Observando a forma de utilização da Praça Agostinho Felício de Faria, foi possível notar que a praça é muito utilizada por famílias de classe média para o lazer. Foram observadas famílias, nas quais a avó, a mãe e a filha estavam na praça; uma conversando, outra olhando o celular e a outra correndo pelos espaços ajardinados.

Os ruídos de veículos quase não existiam, já que os poucos carros que circulavam ao redor da praça o faziam de forma lenta. Apesar da estrutura física da rodoviária estar desativada, os ônibus intermunicipais ficavam parados ao lado da praça e as saídas destes eram marcadas pelas chamadas de embarque.

O coreto e a fonte de água pareciam ser os lugares preferidos das crianças, que sempre corriam para e entre eles. Já os aparelhos de ginásticas, foram os eleitos pelos cidadãos de meia idade. A praça é muito extensa e a fonte de água e o coreto ficam na extremidade baixa, enquanto os aparelhos de ginástica ficam do outro lado. Pela observação foi possível verificar a identificação estabelecida pelos sujeitos com a praça da cidade. A praça é um espaço público, mas como nos ensina David Harvey, nem sempre o espaço público é um espaço comum. É preciso construí-los:

Figura 6: Vista Parcial da Praça Agostinho Felício de Faria/ Natividade da Serra, SP

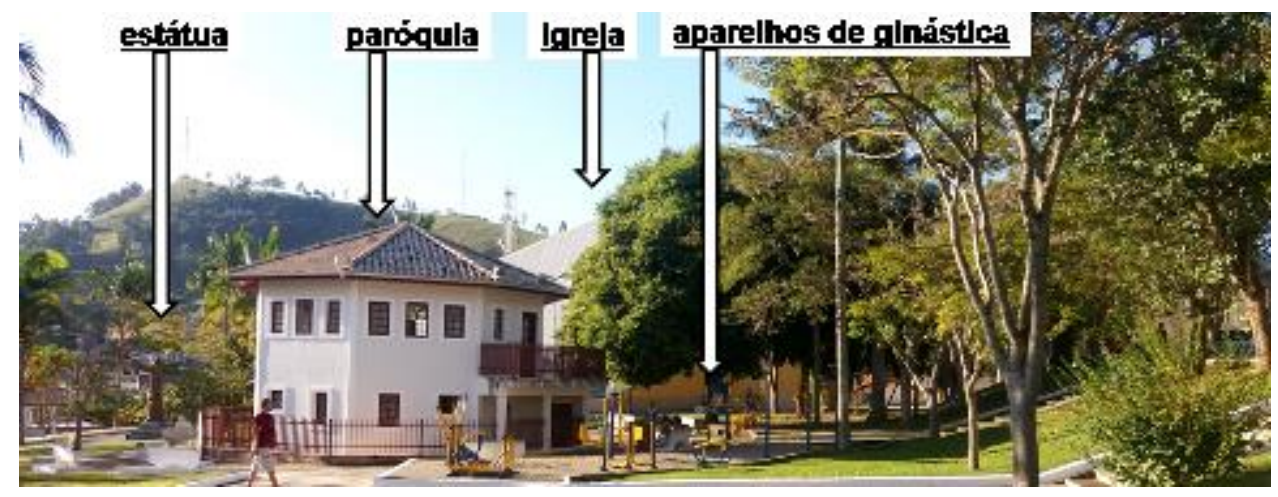

Fonte: Acervo dos autores

Figura 7: O Coreto e os aparelhos de ginástica da Praça Agostinho Felício de Faria/ Natividade da Serra, SP

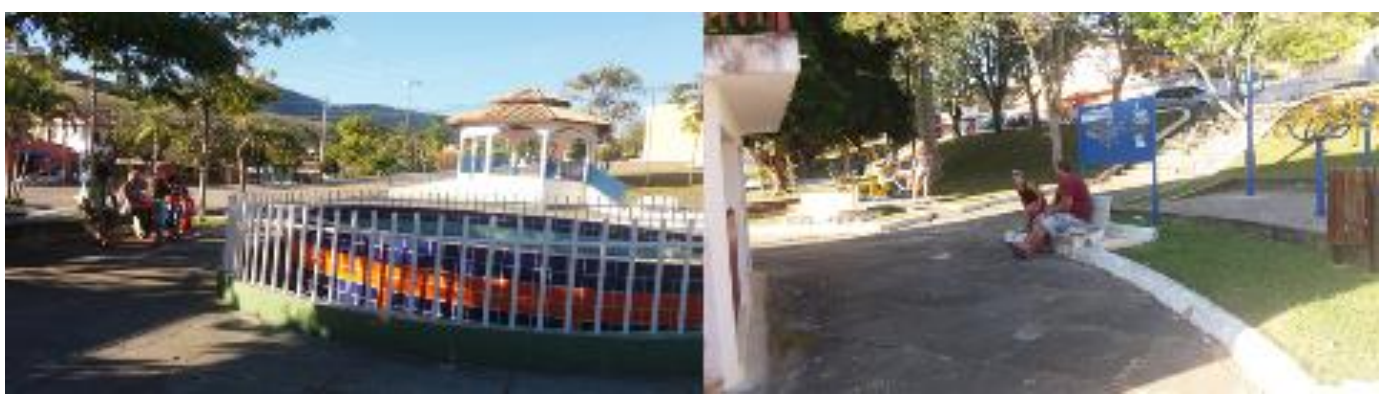

Fonte: Acervo dos autores 
As praças Sintagma, em Atenas, Tahrir, no Cairo, e da Catalunha, em Barcelona eram espaços públicos que se tornaram comuns urbanos quando as pessoas ali se reuniram para expressar suas opiniões políticas e fazer suas reivindicações. A rua é um espaço público que histórica e frequentemente se converte pela ação social em um comum do movimento revolucionário, assim como em um espaço de repressão sangrenta. (HARVEY, 2014, p.144)

Foi possível perceber pelos cartazes existentes na Praça Agostinho Felício de Faria que haviam três festas juninas programadas, uma no dia da visita ao local. Mas todas estas festas iriam acontecer nas escolas e nenhuma na praça. Outro fato relevante de se notar é que a cidade possui 6.770 habitantes e uma praça central tão extensa e com tantos aparelhos não aparenta, num primeiro olhar, fragmentar o espaço e dificultar o encontro.

Em um banco da praça, um homem branco idoso (também aparentando ser de classe média) acompanhado do seu neto, começou a relatar como era bom morar em Natividade da Serra, o que havia acontecido com a chamada "cidade velha", como a "cidade nova" havia sido construída, das suas aventuras como vereador da cidade e o que ele achava do prefeito que havia saído e do recémchegado. Sua narrativa apaixonante foi interrompida pelo neto que se aventurava a subir numa das árvores da praça. Neste relato foi observado um saudosismo pelo espaço da "cidade velha", mas um conformismo com a "cidade nova" e pela "praça nova", devido ao discurso econômico regional da necessidade de represar água para geração de energia.

Após essa observação, a praça Agostinho Felício de Faria, localizada no centro da cidade de Natividade da Serra reflete um conflito local pelo enfrentamento de algumas barreiras como o fato de ter sido construída recentemente, ou seja, não possuir relação histórica com a população e a sua grande extensão territorial. Como também ecoa os debates regionais, já que Natividade da Serra não possui voz ativa institucionalmente no contexto metropolitano e seu espaço público central foi modificado para atender uma demanda gerada majoritariamente pela cidade de São José dos Campos.

\section{Considerações finais}

Utiliza-se da metodologia da observação flutuante, que consiste em olhar atentamente a paisagem e sua dinâmica, gerando um relato que expresse tais experiências, sem a intensão de definilas intimamente, mas se configura numa leitura da dinâmica urbana contemporânea. Para a realização desta análise buscou-se na Região Metropolitana do Vale do Paraíba e Litoral Norte dois espaços públicos centrais em duas cidades díspares.

Sem a pretensão de esgotar o debate, mas de inicialo, este trabalho traçou o que compreende o espaço público urbano no contexto da modernidade líquida. E com tais características analisou-se em que medida ou se tais espaços impactam no processo de construção de cidadania. Após as observações e reflexões traçadas, considera-se que os espaços públicos são palco para as relações sociais, como também são objetos desejados e disputados socialmente. Assim, as praças públicas observadas são, num primeiro momento, uma representação física do resultado de uma disputa social já ocorrida naquele espaço; como observado pela "praça nova" da cidade de Natividade da Serra. Num segundo momento, tais espaços possibilitam o encontro e o confronto entre diferentes que disputam o uso predominante e válido socialmente; como observado na praça da cidade de São José dos Campos.

Relevante pontuar que as duas cidades observadas estão localizadas na mesma região metropolitana, possuem dimensão territorial similar e possuem uma proximidade territorial. Contudo, as características físicas não definem os conflitos regionais, nem os locais. Tais conflitos são determinados, nas diferentes escalas, pelas relações pré-estabelecidas coletivamente, quais 
sejam, as relações econômicas de importâncias de alguns produtos e serviços em detrimento de outros, da produção por meio de hidroelétricas; que ocorrem em concomitância com os posicionamentos políticos e as interações institucionais em conselhos regionais e de decisões de prioridades regionais.

Estes conflitos, mesmo não sendo influenciados diretamente pelo espaço físico, estão refletidos nestes locais. Assim, todo espaço carrega consigo o desfecho de um conflito. $E$ as pessoas que também trazem consigo uma representação social do outro, ou como afirma Jessé Souza pela aceitação coletiva e implícita desigualdade social, tais pessoas adentram neste espaço também reconhecendo onde se situa ali a linha abissal. Não uma linha ou um muro físico, mas a formas físicas, as construções, as cores e as vegetações trazem consigo símbolos da desigualdade social existente. Ou seja, as praças públicas são de todos, mas apropriada por alguns; e os espaços físicos ecoando o desfecho destas lutas se tornam palcos tendenciosos que abrigam outros conflitos.

\section{Agradecimentos}

Os autores agradecem ao Conselho Nacional de Desenvolvimento Científico e Tecnológico $\mathrm{CNPq} /$ Capes, pela bolsa de doutorado concedida a primeira autora. O presente trabalho foi realizado com apoio da Coordenação de Aperfeiçoamento de Pessoal de Nível Superior - Brasil (CAPES) - Código de Financiamento 001.

\section{Refrências}

BAUMAN, Z. Modernidade Líquida. P. DENTZIEN, Trad. Rio de Janeiro: Jorge Zahar Editora. 2001.

DARDOT, P. e LAVAL, C. Comum: ensaio sobre a revolução no século XXI. São Paulo: Boitempo, 2017.

DE CERTEAU, M. A Invenção do Cotidiano. Petrópolis, RJ: Editora Vozes, 1994
HARVEY, D. Cidades Rebeldes: do direito à cidade à revolução urbana. São Paulo: Martins Fontes, 2014

HILLMAN, J. Cidade e Alma.G. Barcellos, \& L. Rosenberg, Trads. São Paulo: Nobel. 1993.

Instituto Brasileiro de Geografia e Estatística - IBGE. (2010). Censo Demográfico - 2010. Rio de Janeiro: IBGE. Recuperado em 06 de abril de 2018, de www.ibge.gov.br

KURKDJIAN, M. L. N. O.; VALERIO FILHO, M.; VENEZIANI, P.; PEREIRA, M. N.;FLORENZANO, T. G.; ANJOS, C. E.; OHARA, T.; DONZELI, P. L.; ABDON, M. N.; SAUSEN, T. M.; PINTO, S. A. F.; BERTOLDO, M. A..; BLANCO, J. G.; CZORDA, S. M. Macrozoneamento da Região do Vale do Paraiba e Litoral Norte do Estado de São Paulo. São José dos Campos. Instituto Nacional de Pesquisas Espaciais, 176p,1992. (INPE - 5381-PRP/165)

LEFEBVRE, H. A produção do espaço. 4. ed. D. B. PEREIRA, \& S. MARTINS, Trads. Paris: Éditions Anthropos. 2006.

LEFEBVRE, H. O Direito à Cidade. São Paulo: Centauro Editora, 2001

MAGNANI, J. G. C. De perto e de dentro: notas para uma etnografia urbana. Revista Brasileira de Ciências Sociais, v. 17, n. 49, p. 11-29, junho 2002.

MONGIN, O. A Condição Urbana: a cidade na era da globalização. 2 ed. Tradução: Letícia Martins de Andrade. São Paulo: Estação Liberdade, 2009.

PÉTONNET, C. Observação flutuante: o exemplo de um cemitério parisiense. Antropolítica: Revista Contemporânea de Antropologia, n. 25. p. 99111, 2. sem. 2008.

ROLNIK, R. O que é Cidade. Coleção primeiros passos n. 203. $4^{\underline{a}}$ reimpressão, $1^{\underline{a}}$ ed. São Paulo : Editora Brasiliense, 1995.

SANTOS, B. S. Para além do pensamento abissal: das linhas globais a uma ecologia de saberes. Revista crítica de ciências sociais, n. 78, p. 7194, 2007.

SANTOS, B. S. Toward a New Common Sense: Law, Science and Politics in the Paradigmatic Transition. Nova lorque : Routledge, 1995.

SANTOS, M. O Espaço do Cidadão. 5 ed. São Paulo: Studio Nobel, 2000. 
SOUZA, J. A gramática social da desigualdade brasileira. In J. Souza (Org.). A invisibilidade da desigualdade brasileira. p. 23-53. Belo Horizonte, MG: Editora UFMG, 2006.

VAINER, C. B. Pátria,empresa e mercadoria. Notas sobre a estratégia discursiva do Planejamento Estratégico Urbano. In: O. ARANTES, E. MARICATO, \& C. VAINER, A cidade do pensamento único: desmanchando consensos. 3 ed., p. 75-103. Petrópolis: Vozes. 2002.

POSSAMAI, Paulo César. O processo de construção da identidade ítalo sul-riograndense (18751918). In: Revista Unisinos. V.11.no 1. 2007 (p.49-57).

MACIEL, Maria Eunice. Patrimônio, tradição e tradicionalismo: o caso do gauchismo, no Rio Grande do Sul. In: Revista de Humanidades MNEME. V.07. N. 18, out./nov. de 2005. (439460p).

SANTIN, Silvino. Caminhos da imigração italiana no Rio Grande do Sul (I), 2008. https://silvinosantin.wordpress.com/ <Acesso em 22.02 2017>.

VIZZOTTO, Jacinta Maria Pivetta. História de fé e trabalho: bens culturais de Vale Vêneto. (Dissertação de Mestrado). Santa Maria: Universidade Federal de Santa Maria, 2014.

ZANINI, Maria Catarina. Comida e simbolismo entre os italianos no Rio Grade do Sul (Brasil). In: Cadernos Espaço Feminino, v.19, no1, jan/jul 2008 (p.255-284). 